\title{
Identificação de manifestações patológicas em unidade educacional de Castro Alves - BA: um estudo de caso
}

\author{
R. Santos ${ }^{1 *}$, L. Farias ${ }^{2}$, L. De Sousa ${ }^{3 *}$ \\ *Autor de Contato: 1ucarb08@gmail.com \\ ${ }^{1,3}$ Faculdade de Engenharia civil, Faculdade de Ciências e Empreendedorismo, FACEMP, Santo Antônio de Jesus, \\ Brasil \\ ${ }^{2}$ Programa de Engenharia Civil, Universidade Federal do Rio de Janeiro, Rio de Janeiro, Brasil
}

\begin{abstract}
RESUMO
As manifestações patológicas podem surgir pelo envelhecimento e ação de intempéries, comprometendo a funcionalidade da estrutura ou outros componentes de uma edificação. No entanto, quando ocorrem na fase construtiva evidenciam problemas na execução, acarretando prejuízos financeiros e atraso na conclusão da obra. Este artigo tem como finalidade analisar manifestações patológicas em uma unidade educacional pública em fase construtiva, localizada no município de Castro Alves - Bahia, Brasil. Foram identificadas fissuras ou trincas devido à corrosão de armadura em concreto armado, em alvenarias, pela ausência de vergas ou contravergas em aberturas de portas ou janelas. Identificou-se manchas de umidade, lixiviação e de corrosão que evidenciam incidência de água de chuva constante. Estas manifestações indicam falhas durante a execução e planejamento da obra.
\end{abstract}

Palavras-chave: Manifestações patológicas; fase construtiva; construção civil. 


\begin{abstract}
Pathological manifestations can arise from aging and the action of weather, compromising the functionality of the structure or other components of a building. However, when they occur in the construction phase, they show problems in execution, resulting in financial losses and delays in completing the work. This article aims to analyze pathological manifestations in a public educational unit under construction, located in the municipality of Castro Alves - Bahia, Brazil. Cracks were identified due to corrosion of reinforced concrete reinforcement, in masonry, due to the absence of lintels or counter lintels in door or window openings. Moisture, leaching and corrosion stains were identified, showing constant incidence of rainwater. These manifestations indicate failures during the execution and planning of the construction.
\end{abstract}

Keywords: Pathological manifestations; constructive phase; construction.

\title{
RESUMEN
}

Las manifestaciones patológicas pueden surgir por el envejecimiento y la acción del mal tiempo, comprometiendo la funcionalidad de la estructura $u$ otros componentes de un edificio. Sin embargo, cuando ocurren en la fase de construcción, presentan problemas en la ejecución, resultando en pérdidas económicas y retrasos en la finalización de la obra. Este artículo tiene como objetivo analizar las manifestaciones patológicas en una unidad educativa pública en construcción, ubicada en el municipio de Castro Alves - Bahía, Brasil. Se identificaron fisuras o fisuras por corrosión de armaduras de hormigón armado, en mampostería, por ausencia de dinteles o contra dinteles en aberturas de puertas o ventanas. Se identificaron manchas de humedad, lixiviación y corrosión, que muestran una incidencia constante de agua de lluvia. Estas manifestaciones indican fallas durante la ejecución y planificación de la obra.

Palabras clave: Manifestaciones patológicas; fase constructiva; construcción civil.

\section{INTRODUÇÃO}


A patologia ficou conhecida, no ramo da engenharia, como a ciência que investiga as origens e mecanismos de ocorrência de inconformidades que afetam aspectos estruturais e estéticos da edificação (Helene, 2003; Nazário e Zacan, 2011). As manifestações patológicas podem ser oriundas do uso de materiais inadequados, falhas na execução ou pela ausência de manutenção na estrutura ou outros componentes da construção. Também ocorrem efeitos adversos com a ação de intempéries resultando na deterioração e envelhecimento da estrutura, então resultando em diminuição do desempenho da edificação (Costella et al., 2015).

De modo a evitar problemas na execução de uma construção é necessário projeto bem detalhado, com informações claras e precisas, além do planejamento verosímil e controle eficiente das etapas construtivas, com investimentos em mão de obra qualificada e materiais de qualidade (Caporrino, 2018). Logo, se não for adequadamente executado, podem surgir manifestações patológicas como fissuras, trincas ou rachaduras, falhas de impermeabilização, indicando que a estrutura e os sistemas construtivos não possuem desempenhos adequado (Thomaz, 1998).

De acordo com Lapa (2008), as manifestações patológicas também estão relacionadas à velocidade de expansão do mercado da construção civil, pois houve a adesão à novas tecnologias construtivas e absorção de mão de obra de baixa qualificação. A NBR 6118 (Associação Brasileira de Normas Técnicas, 2014) e NBR 15575 (Associação Brasileira de Normas Técnicas, 2013) são normas que evidenciam a relevância da durabilidade da estrutura e o desempenho da edificação, respectivamente.

Os cuidados para que a edificação seja durável abrange desde a fundação dimensionada de acordo com a resistência do solo e efetuando-se a impermeabilização (Milititsky, 2015). Os projetos da superestrutura (pilares, lajes e vigas) devem interagir com a fundação, a fim de evitar problemas de recalques e deformações excessivas em elementos estruturais (Veloso e Lopes, 2010).

De acordo com Lottermann (2013), as manifestações patológicas com surgimento em período inferior a 2 anos se relacionam às fases de planejamento, projeto, fabricação e construção. Enquanto, aquelas que surgem ao longo de um tempo maior podem ser relacionadas a utilização. Holanda (2015) sugere que causas químicas da deterioração de materiais cimentícios podem ser agrupadas em três categorias. Estas categorias são a hidrólise dos componentes da pasta de cimento hidratada por água pura, trocas iônicas entre agentes agressivos dissolvidos em fluidos e compostos do cimento hidratado e reações com produtos expansivos com reação de sulfatos, reação álcaliagregado e corrosão da armadura no concreto.

Diante da problemática do constante surgimento de manifestações patológicas em construções, sendo ainda mais grave sobre ponto de vista econômico, quando tem origem na entrega da obra ou antes deste evento, faz com que seja relevante estudar os motivos que levam a este fato, de modo a evitar situações similares. Neste trabalho foram analisadas as manifestações patológicas de uma Unidade Educacional Pública, no município de Castro Alves-BA, bem como as principais causas do seu surgimento e possíveis reparos a serem realizados na obra.

\section{METODOLOGIA}

Foi realizado um estudo de caso em uma unidade educacional com 12 salas padrão Fundo Nacional de Desenvolvimento da Educação (FNDE) (Figura 1), no município de Castro Alves-BA, possui $3.228,08 \mathrm{~m}^{2}$ de área construída, distribuídas em blocos, conforme a Figura 2. 


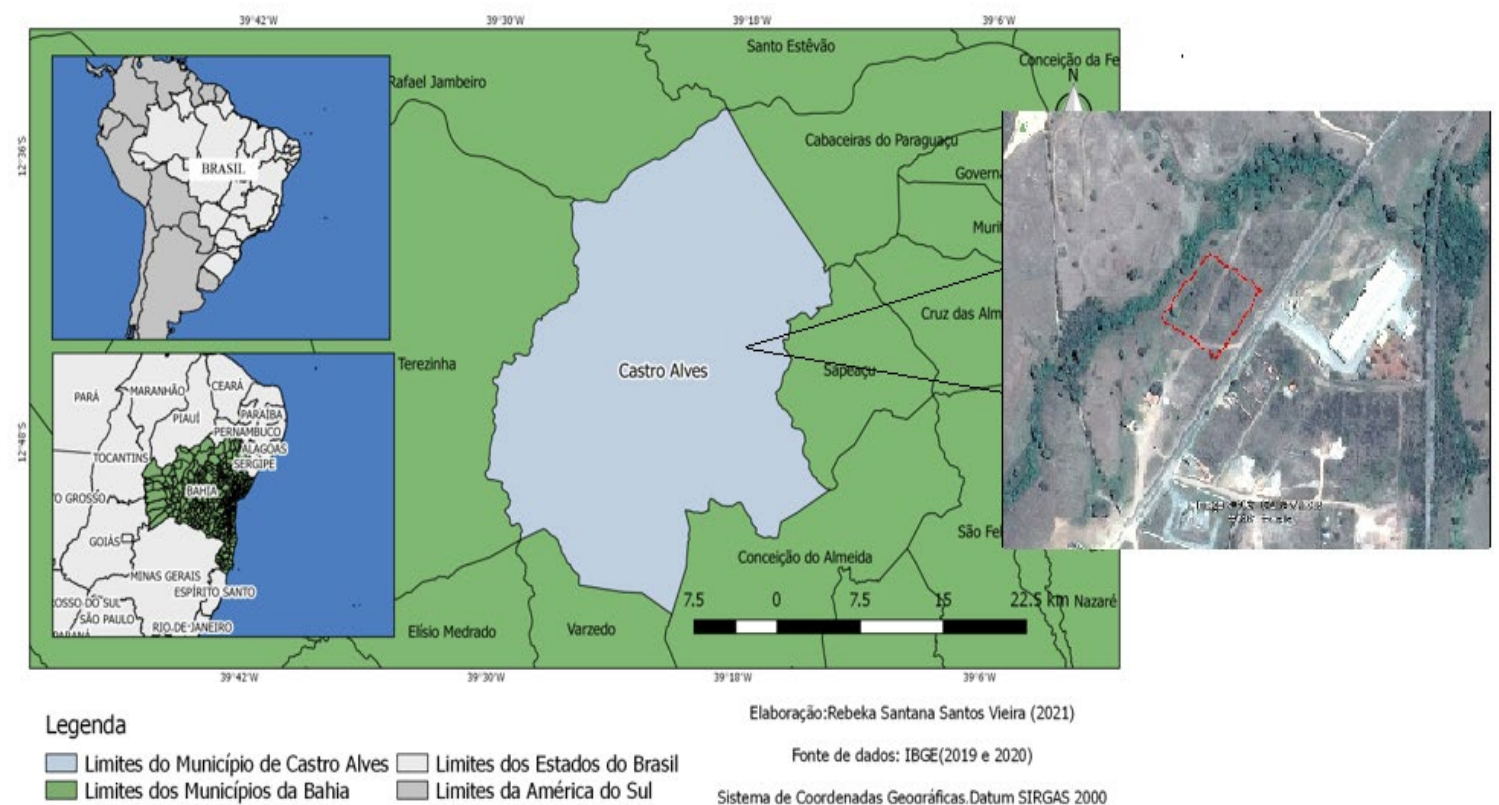

Figura 1. Localização da escola no Municipio de Castro Alves, Bahia.

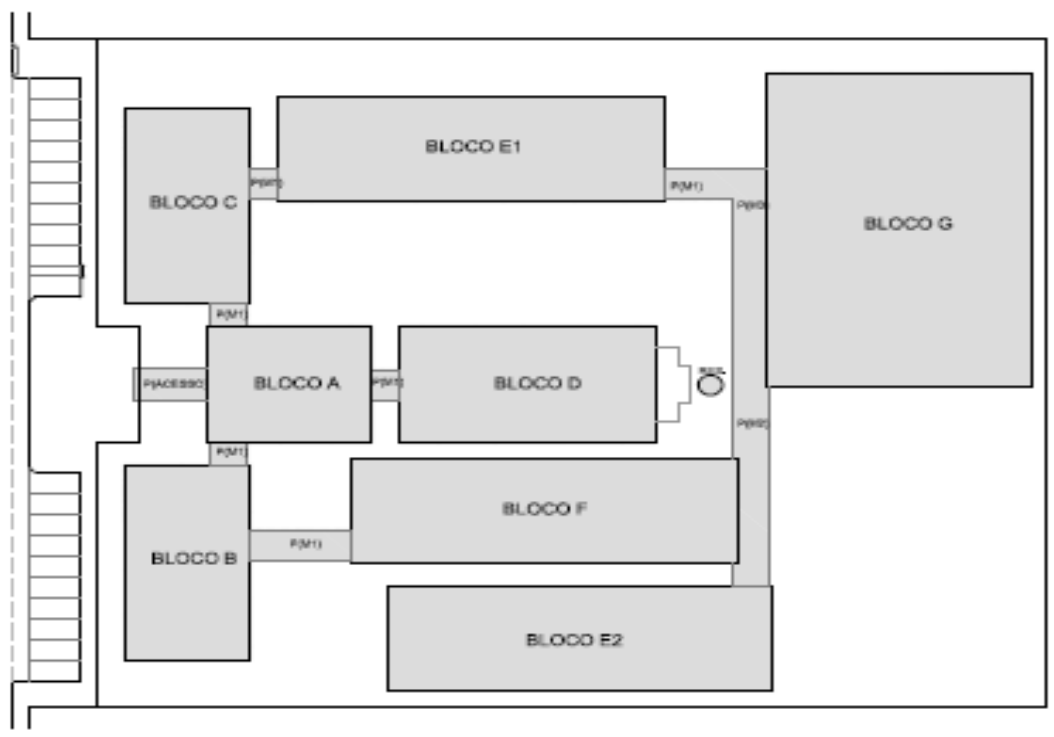

Figura 2. Croqui de referência da obra.

A edificação está em fase de desenvolvimento (Figura 3). A obra foi paralisada aproximadamente por 120 dias, houve alteração da empresa responsável pela execução. A empresa encarregada pela continuidade da obra necessitou analisar e reparar problemas encontrados na estrutura, alvenarias e piso.

A edificação é composta por uma estrutura mista, com cobertura metálica, e sistema de vigas e pilares em concreto armado e a alvenaria como elemento de vedação de bloco cerâmico. 


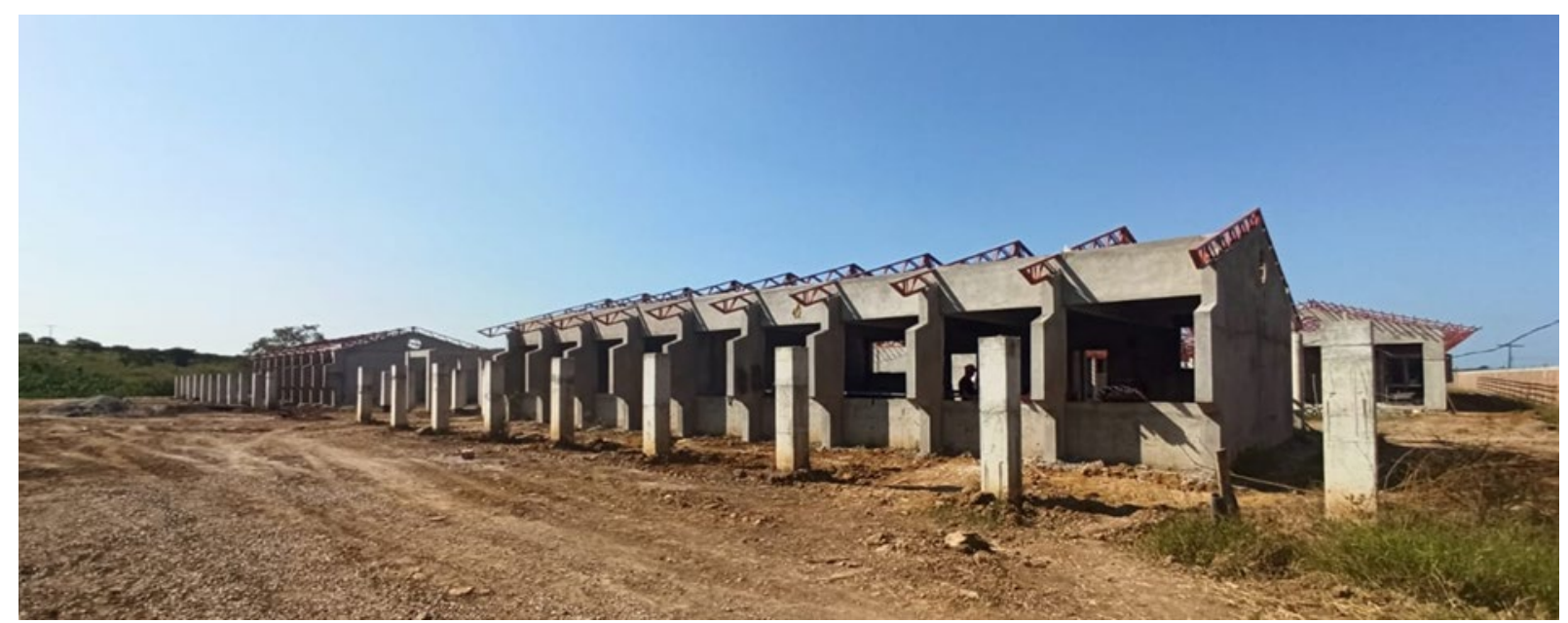

Figura 3. Perspectiva da fachada da obra.

Para o estudo de caso foi realizada uma vistoria da obra, em janeiro de 2021, identificando visualmente as manifestações patológicas, efetuando-se registros fotográficos para análise e busca de possíveis causas, prevenção e tratamentos. A análise e discussão foi embasada na literatura especializada (artigos, monografias, dissertação, tese e livros) sobre o tema: manifestações patológicas em edificações.

\section{RESULTADOS}

\subsection{Identificação das manifestações patológicas e avaliação das possíveis causas}

A fissuração mapeada (Figura 4) foi encontrada em algumas alvenarias, esta manifestação é resultante do processo de retração da argamassa de revestimento ao perder água. Em geral, estas fissuras podem surgir de dilatação devido à ação térmica e hidroscópica no revestimento.

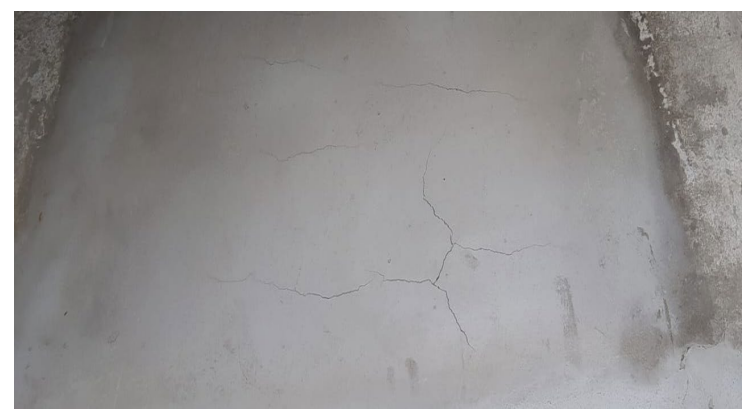

Figura 4. Fissuras mapeadas na argamassa na parede externa do bloco F.

A depender da qualidade da argamassa, um traço inadequado ou ausência do processo de cura pode resultar em fissuras de retração que podem ser agravadas por efeitos térmicos (Farias et al., 2017, Oliveira et al. 2019). Ao consultar Thomaz (1989), percebe-se que a retração causa diminuição do volume do material o que leva ao surgimento de fissuras. Contudo, trata-se de uma manifestação patológica não relacionada a problemas estruturais (Farias et al., 2017).

Nas aberturas de vãos nas alvenarias para portas e janelas foram encontradas trincas, Figura 5 (a) e (b), ocasionadas pelo acréscimo de tensões nas áreas ao lado da abertura onde há alvenaria. O surgimento destas trincas tende a ocorre com inclinações de $45^{\circ}$ nos cantos das aberturas. 
(a)
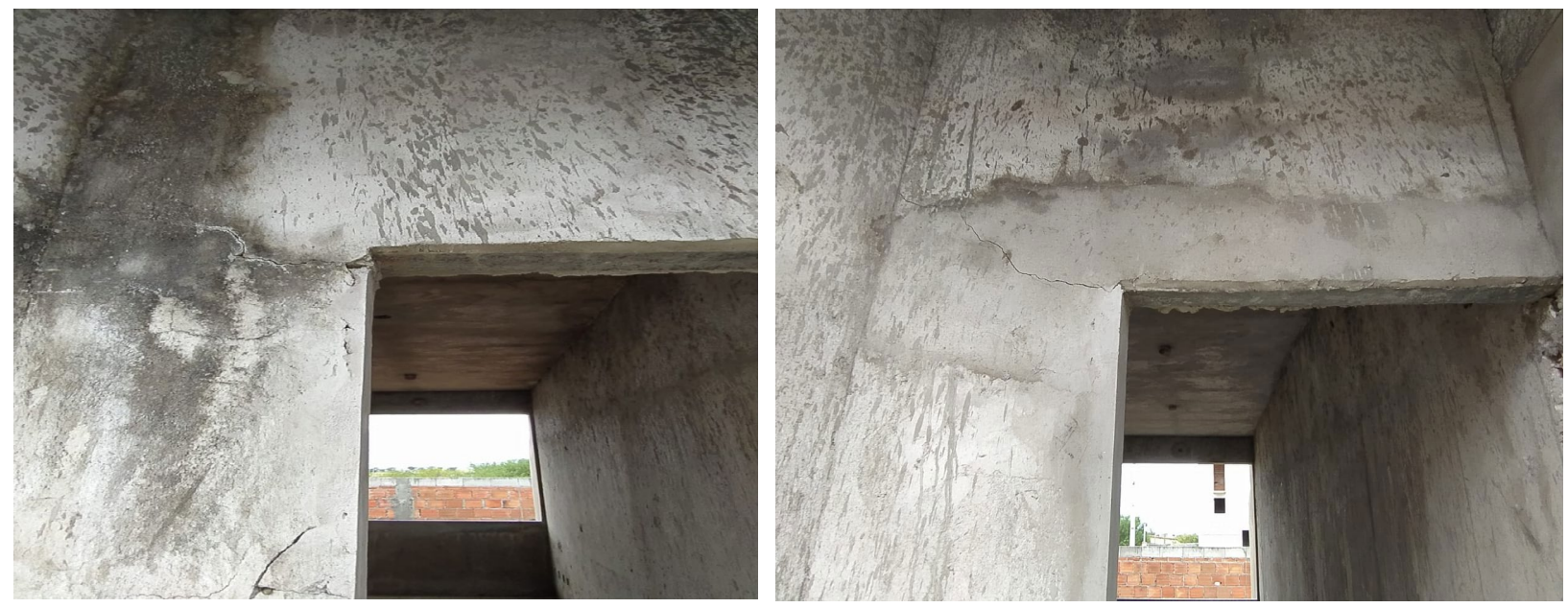

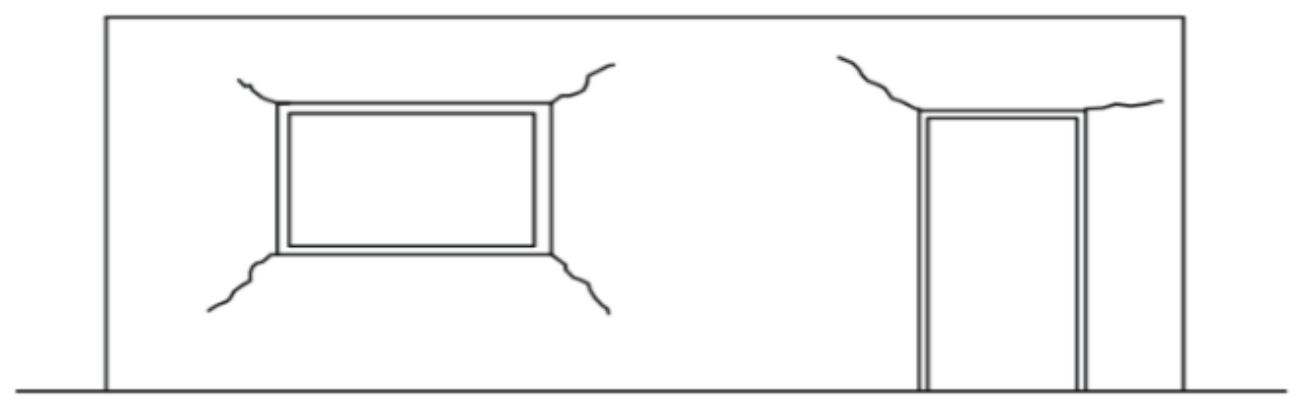

(c)

Figura 5. Trincas no canto das aberturas da porta devido à sobrecargas na alvenaria a) e b), representação de fissuras ou trincas de acordo com Thomaz (1989).

Na Figura 5 (c) é representado um modelo teórico de padrões de fissuras por ausência de vergas (vigas de pequenas dimensões contendo reforço de aço localizadas acima de aberturas de janelas ou portas) e contravergas (vigas de pequenas dimensões contendo reforço de aço localizadas abaixo de aberturas da janela).

O surgimento de fissuras próximas as aberturas, segundo Thomaz (1989) deve-se a sobrecarga causada por carregamentos de compressão excessivos a partir dos vértices da abertura. A NBR 8545 (Associação Brasileira de Normas Técnicas, 1984), informa que as vergas e contravergas devem exceder a largura do vão de pelo menos $20 \mathrm{~cm}$ de transpasse para cada lado e ter altura mínima de $10 \mathrm{~cm}$. A execução incorreta deste elemento, não respeitando as dimensões mínimas ou a ausência dele é a principal causa do surgimento de fissuras ou trincas próximas as aberturas para esquadrias. 


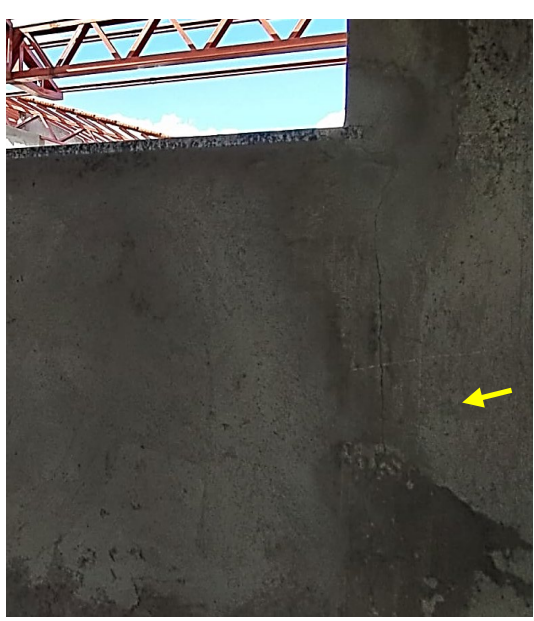

(a)

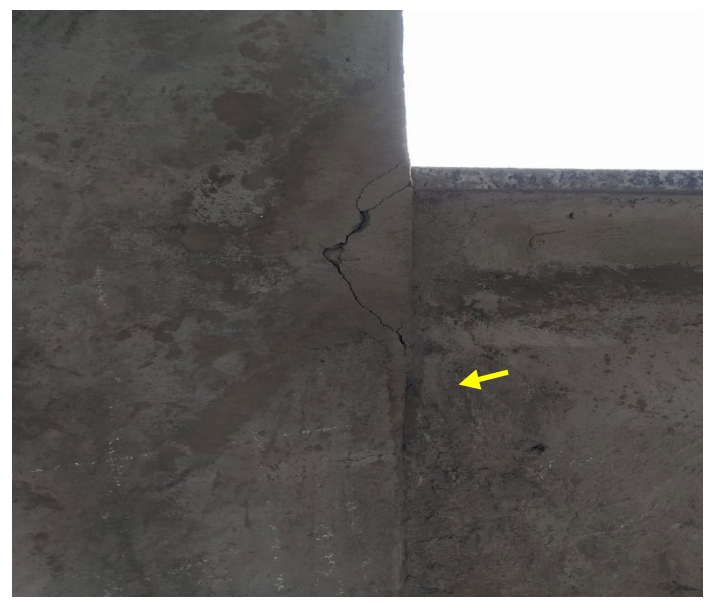

(b)

Figura 6. Trincas e manchas de fluxo de água no peitoril da janela (a) e (b).

A trinca na extremidade inferior da janela e manchas de umidade foram observadas na argamassa de revestimento evidenciadas na Figura 6. As trincas na parte inferior das janelas se relacionam à ausência de contraverga ou na execução inadequada desta. Além disso, se houver maior exposição a água, aumenta-se os riscos de formação de fissuras e trincas geradas pela corrosão da armadura da contraverga, se esta for construída. A ausência de vedação das aberturas durante o período em que a construção foi interrompida pode ter favorecido a incidência de água e surgimento de manchas.

Os peitoris são detalhes arquitetônicos que também tem a função de não permitir o escoamento de água de chuva pela parede, logo a instalação inadequada por erro de execução, a exemplo de inclinação incorreta podem causar problemas na região localizada. De acordo com Thomaz (1989) deve-se substituir peitoris e executar de forma adequada.

Em relação a elementos estruturais em concreto armado, observa-se na viga (Figura 7) a formação de uma trinca que pode ser resultante da movimentação da viga, devido à variação de temperatura e umidade do ambiente externo. A ocorrência destas fissuras ou trincas pode estar relacionada à corrosão do aço do estribo, inferindo-se pelo posicionamento da fissura e manchas com coloração de ferrugem. Em casos de fissuras inferiores a 0,3 mm é indispensável tratamento (Helene, 1992).

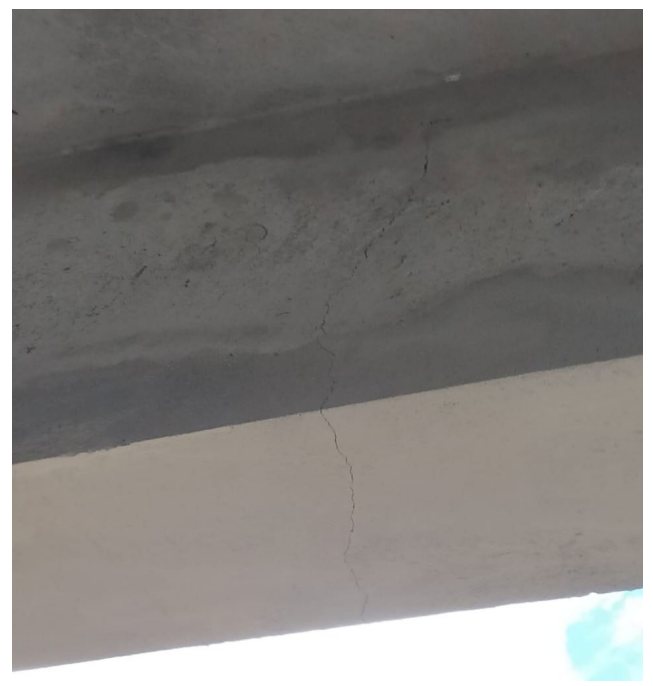

(a)

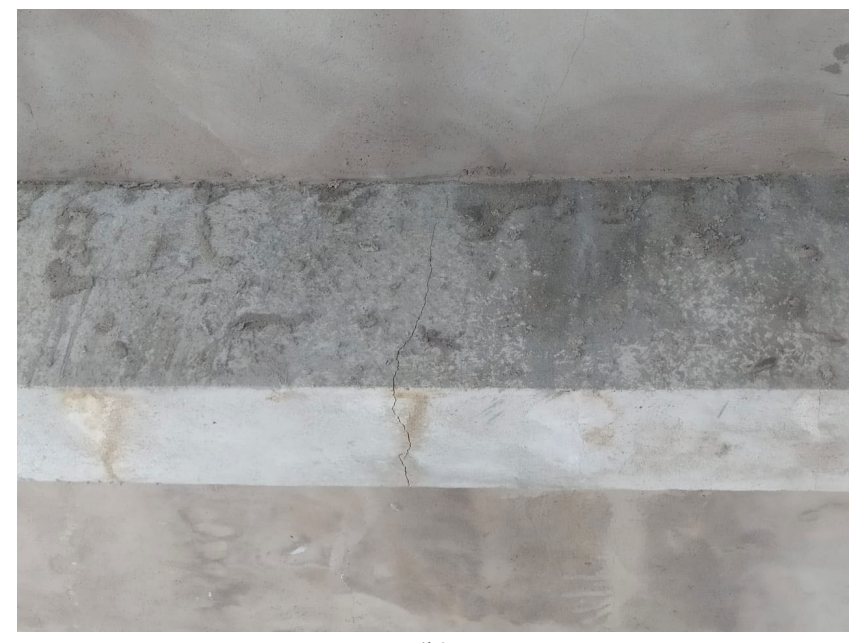

(b)

Figura 7. Fissura localizada na viga (a) e (b). 
Na Figura 8 é evidenciada uma trinca ao longo da altura do pilar, isto pode ter ocorrido devido à corrosão e expansão do aço, nota-se que nesta área há manchas de umidade, indicando que houve incidência de água potencializando a corrosão e fragilizando o concreto. Além do caso observado, fissuras em pilares podem indicar sobrecarga excessiva (Thomaz, 1989).

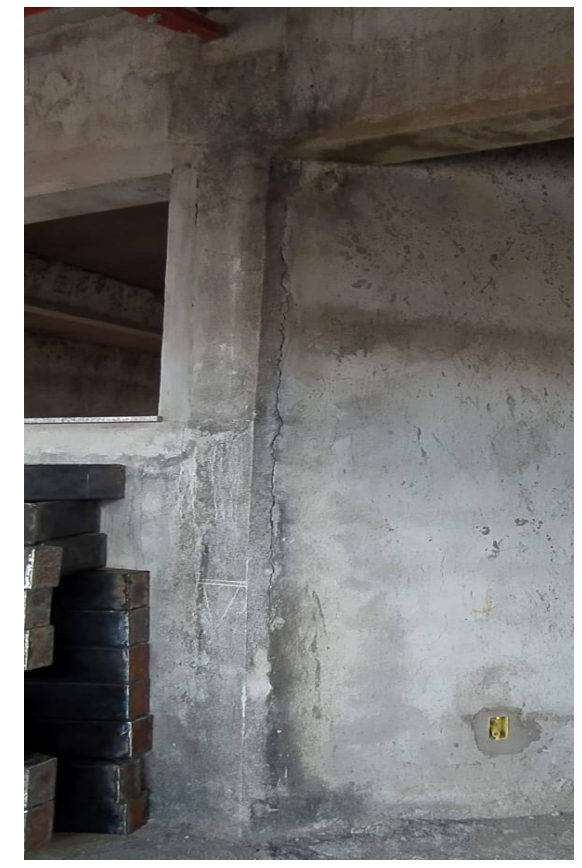

(a)

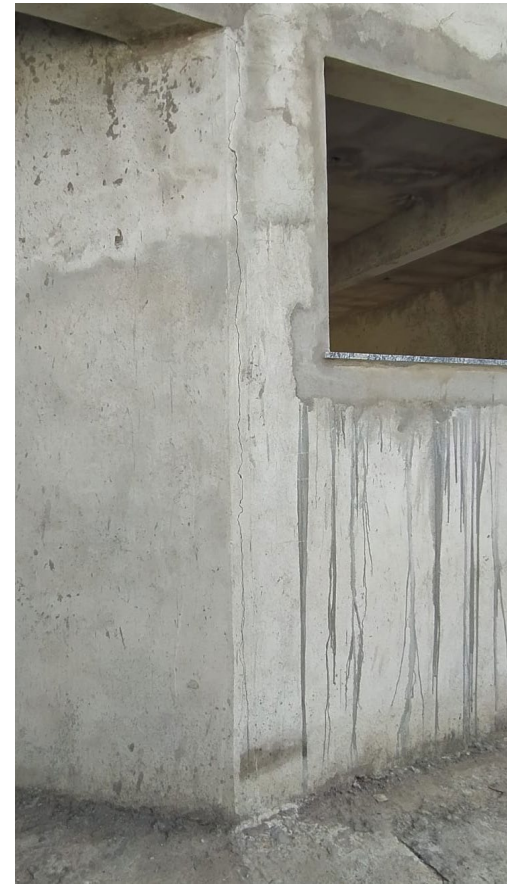

(b)

Figura 8. Trinca localizada no pilar (a) e (b).

Na obra foi identificada na Figura 9 uma trinca horizontal localizada na alvenaria sobre a qual se apoia treliças metálicas que servem como suporte do telhado.

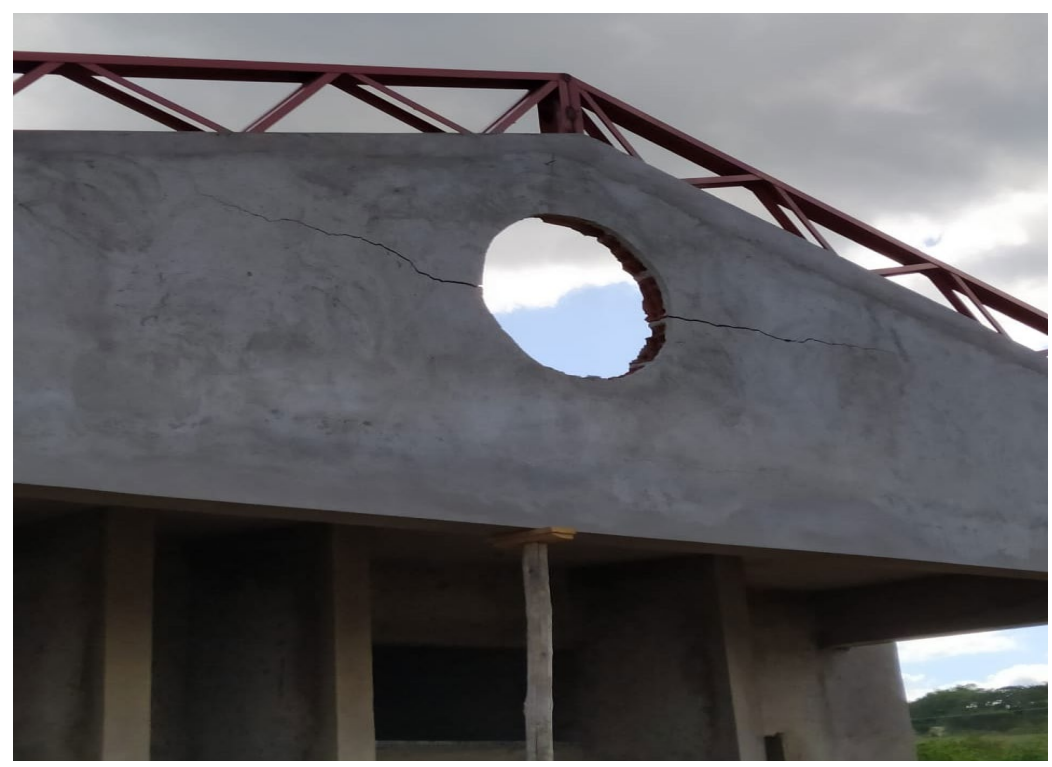

Figura 9. Fissura localizada na alvenaria da fachada.

Esta trinca na alvenaria (Figura 9) ocorre, pois, a alvenaria não é capaz de resistir a momentos fletores provocados por forças transversais ao plano da alvenaria. Estas forças podem ser oriundas 
do processo de montagem da peça metálica, bem como pela pressão do vento. Neste caso, seria preciso o reforço estrutural com vigas e pilares de concreto armado na platibanda para absorver esforços do vento e da cobertura. Tal como aponta Thomaz (1989) as fissuras ou trincas horizontais também podem surgir por compressão dos componentes (junta da argamassa ou dos septos dos blocos de furos horizontais e tijolos) em razão ao excesso de carregamento de compressão na parede ou por possíveis solicitações de flexocompressão.

Outras manifestações patológicas observadas que se relacionam a umidade são observadas na Figura 10, Figura 11 e Figura 12, sendo evidenciadas em manchas na superfície dos elementos, devido à incidência de água de chuva e poeira presente no ambiente. O tempo maior de contato da água na superfície porosa da argamassa maior é a possibilidade de aparecimento de manchas.

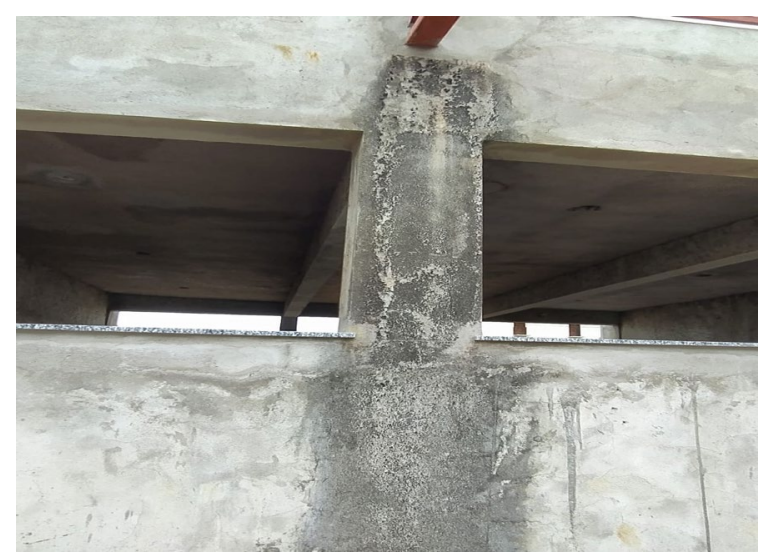

(a)

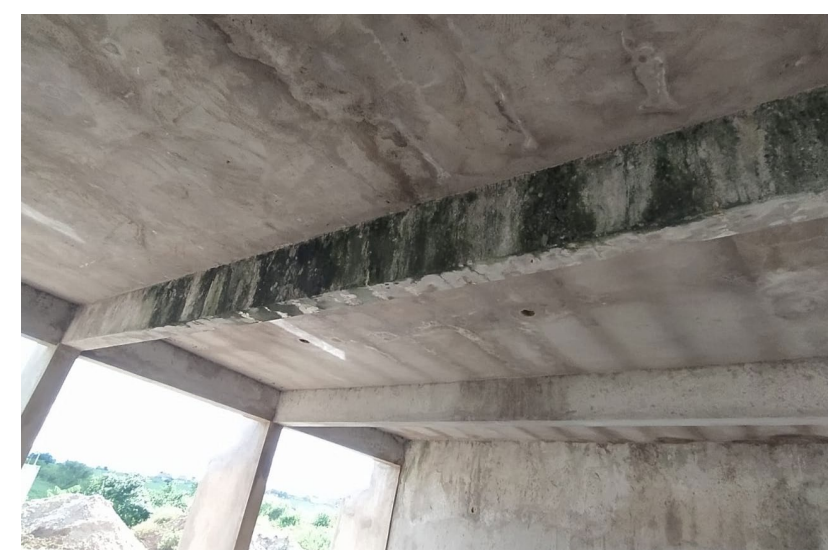

(b)

Figura 10. Mancha de umidade (a) Viga com manchas de umidade, bolor e exsudação de hidróxido de cálcio (b).

$\mathrm{Na}$ Figura 10 b) nota-se uma viga com manchas de sujeira de coloração escura que podem reter mais umidade e agravar a situação da peça estrutural. As manchas esbranquiçadas são evidências de exsudação do hidróxido de cálcio $\left[\mathrm{Ca}(\mathrm{OH})_{2}\right]$ composto produzido na hidratação do cimento que é passível de ser lixiviado pela água da chuva. Este problema observado em uma viga pode comprometer a estrutura ao causar corrosão da armadura e gerar vazios no elemento estrutural.

Werneck et al. (2020) afirma que manchas ou eflorescência são causadas pela permeabilidade do do material cimentício, sendo favorecido por fissuras, percolando à água e promovendo a dissolução e carreamento do $\mathrm{Ca}(\mathrm{OH})_{2}$ do cimento hidratado. Após o $\mathrm{Ca}(\mathrm{OH})_{2}$ ser levado à superfície pela água, este se precipita quando a água é evaporada.

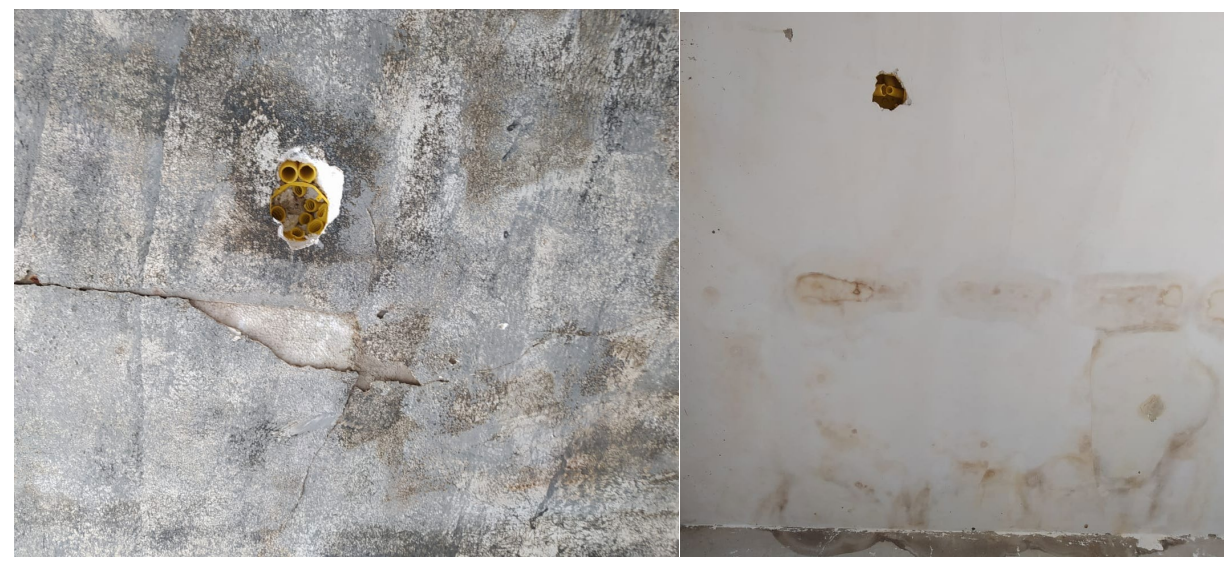

Figura 11. Laje com sinais de umidade e bolor, descascamento do revestimento e detalhe da caixa de passagem elétrica. 
Na Figura 11 nota-se manchas esbranquiçadas e escurecidas, indicando a exsudação do hidróxido de cálcio e bolor, respectivamente, favorecidos pela presença de umidade no local. Nesta imagem nota-se o descascamento do revestimento da superfície da laje, sendo também resultado da variação da umidade e carbonatação que formam produtos expansivos (WERNECK et al., 2020). Ainda se percebe excesso de eletrodutos na caixa de passagem da rede elétrica, indicando instalação não conforme norma NBR 5410 (ABNT, 2004).

Durante a inspeção foram percebidas falhas oriundas do processo executivo, a exemplo da Figura 12, há falhas na concretagem do pilar oriundas de falta de adensamento do concreto.

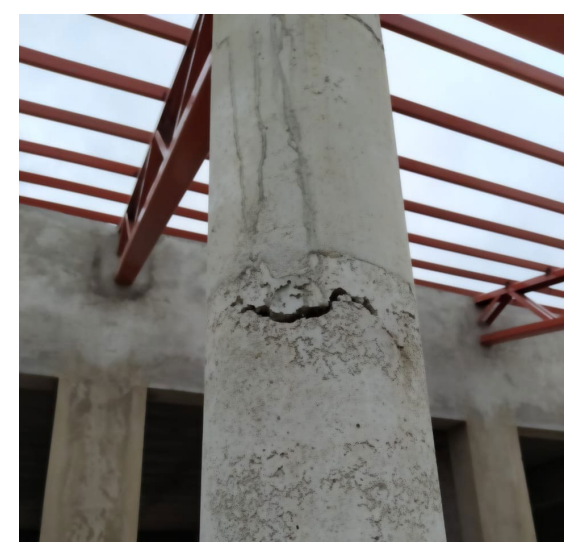

Figura 12. Falhas na concretagem do pilar.

Também foram percebidos algumas tentativas de correção de manifestações patológicas como a inserção de armadura de aço e argamassa costurando a fissura como verificado na Figura 13. Segundo Souza e Ripper (1998) esta técnica é conhecida como grampeamento para o tratamento de fissuras ativas que acontecem sobre linhas isoladas, esta armadura é disposta para combater o esforço extra de tração que provocou a fendilhação. No entanto, está técnica pode não ser adequada pois pode transferir a fissura para região adjacente, especialmente quando as fissuras ocorrem na alvenaria que não possui resistência à esforços mecânicos.

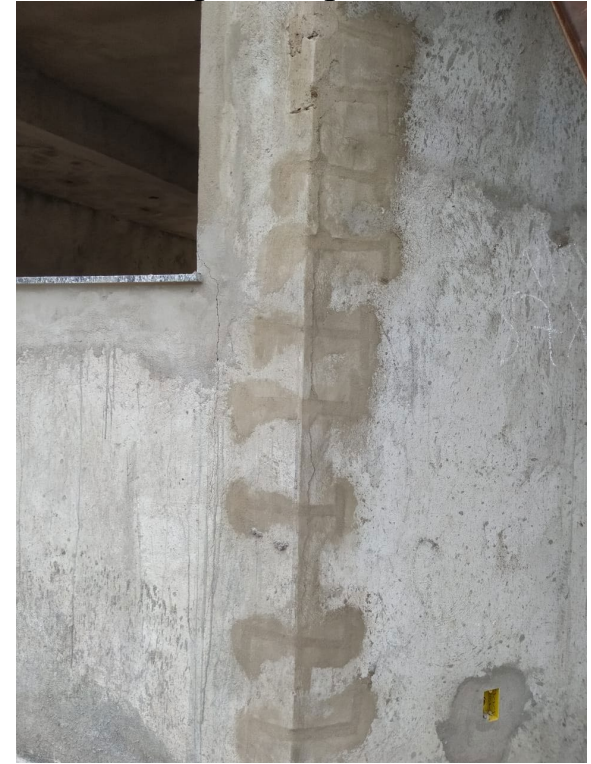

(a)

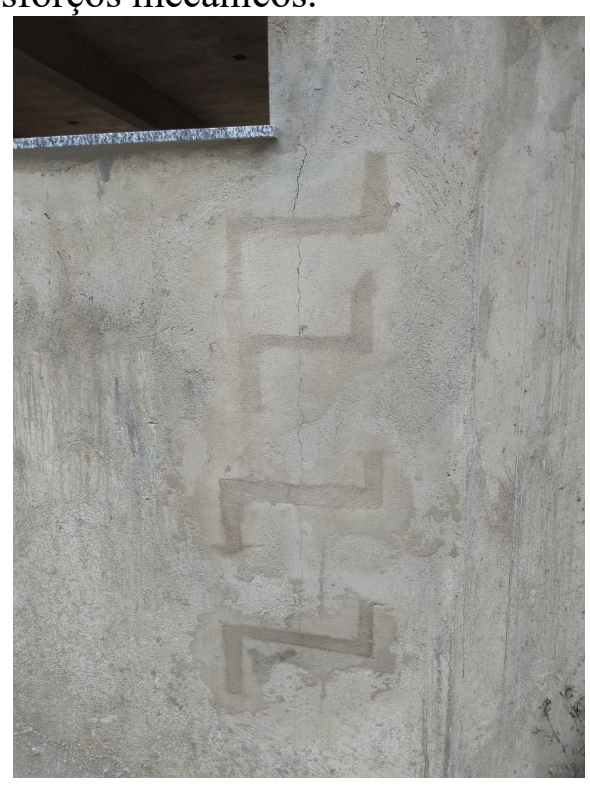

(b)

Figura 13. Procedimentos de reparos para controle de algumas fissuras (a) e (b). 
Para as manifestações patológicas observadas foram expostos na Tabela 1 alguns procedimentos de prevenção e solução que podem servir como base e ser aplicadas na obra objeto de estudo.

Tabela 1. Procedimentos de prevenção e Correção das manifestações identificadas.

\begin{tabular}{|c|c|c|c|}
\hline $\begin{array}{c}\text { Diagnóstico } \\
\text { patológico }\end{array}$ & Solução & Prevenção & Referências \\
\hline $\begin{array}{l}\text { Mofo, } \\
\text { bolor }\end{array}$ & $\begin{array}{l}\text {-Lavar toda área afetada com } \\
\text { escova de aço ou pano e uma } \\
\text { mistura de água sanitária e água } \\
\text { potável na proporção } 1: 1 \text {; } \\
\text { deixar a soluça agir } \\
\text { aproximadamente } 4 \text { (quatro) } \\
\text { horas lavar com água a fim de } \\
\text { eliminar resíduos de água } \\
\text { sanitária; repetir até o mofo seja } \\
\text { eliminado. }\end{array}$ & $\begin{array}{l}\text { - Projetar locais arejados, } \\
\text { bem ventilados e evitar } \\
\text { infiltração de umidade nas } \\
\text { paredes por água da chuva } \\
\text { ou ascendente do solo ou } \\
\text { por falha nas instalações } \\
\text { com água. }\end{array}$ & $\begin{array}{l}\text { Gaspar (2009) } \\
\text { Helene }(1992) \\
\text { NBR } 7200(1998) \\
\text { Verçoza }(1991)\end{array}$ \\
\hline $\begin{array}{l}\text { Goteiras e } \\
\text { manchas de } \\
\text { umidade }\end{array}$ & $\begin{array}{l}\text {-Retirada de todo reboco } \\
\text { desprendido; } \\
\text {-Execução de novo reboco com } \\
\text { aditivo impermeabilizante. }\end{array}$ & $\begin{array}{l}\text {-Aplicação de elementos } \\
\text { arquitetônicos } \\
\text { (pingadeiras). }\end{array}$ & \\
\hline $\begin{array}{l}\text { Fissuras em } \\
\text { vigas de } \\
\text { retração } \\
\text { hidráulica } \\
\text { ou térmica }\end{array}$ & $\begin{array}{l}\text { - Evitar a secagem prematura do } \\
\text { concreto (cura inadequada); } \\
\text {-Recuperar ou reforçar o } \\
\text { componente estrutural. }\end{array}$ & $\begin{array}{l}\text { - Fissuras abaixo de } 0,1 \mathrm{~mm} \\
\text { sem consequência; } \\
\text { - Abertura < ou igual } 0,1 \\
\text { mm, é dispensado qualquer } \\
\text { tratamento; } \\
\text { - Abertura > ou igual } 0,3 \\
\text { mm ativa, colmatar com } \\
\text { selante. }\end{array}$ & $\begin{array}{l}\text { Thomaz (1989), } \\
\text { Casotti (2007), } \\
\text { NBR ABNT } \\
\text { 9575/2010; } \\
\text { Zanzarini } \\
(2016) \text {. }\end{array}$ \\
\hline $\begin{array}{l}\text { Fissuração } \\
\text { mapeada }\end{array}$ & $\begin{array}{l}\text { - Novo revestimento } \\
\text { empregando adesivo base } \\
\text { acrílica ou base epóxi como } \\
\text { ponte de aderência; } \\
\text { - Colmatar as fissuras com } \\
\text { estucamento. }\end{array}$ & $\begin{array}{l}\text {-Melhorar a cura; } \\
\text {-Melhorar o acabamento } \\
\text { - Controle do excesso de } \\
\text { água de amassamento. }\end{array}$ & $\begin{array}{ll}\text { Thomaz } & \text { (1989), } \\
\text { Souza; Ripper } \\
\text { (1998), Zanzarini } \\
\text { (2016). }\end{array}$ \\
\hline $\begin{array}{l}\text { Fissura em } \\
\text { pilar }\end{array}$ & $\begin{array}{l}\text { - Retirar o concreto afetado e } \\
\text { produtos da corrosão; } \\
\text { - Repor a seção original da } \\
\text { armadura; } \\
\text { - Se houver agentes agressivos, } \\
\text { efetuar a correção com primer } \\
\text { para proteção da armadura; } \\
\text { - Aumentar a seção do pilar; } \\
\text { - Aplicar revestimento de } \\
\text { proteção. }\end{array}$ & 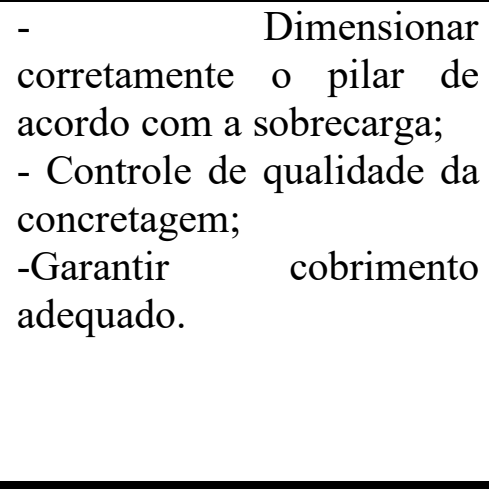 & Brito (2017) \\
\hline
\end{tabular}


Tabela 1. Continuação.

\begin{tabular}{|c|c|c|c|}
\hline $\begin{array}{c}\text { Diagnóstico } \\
\text { patológico }\end{array}$ & Solução & Prevenção & Referências \\
\hline Eflorescência & $\begin{array}{l}\text { - Renovação do revestimento } \\
\text { com escova de aço, limpeza } \\
\text { com solução de ácido } \\
\text { muriático; } \\
\text { - Retirar a película, eliminar a } \\
\text { causa da infiltração, secar } \\
\text { substrato antes de pintar. }\end{array}$ & $\begin{array}{l}\text { - Verificação de possíveis } \\
\text { infiltração. }\end{array}$ & $\begin{array}{l}\text { Helene (1992) } \\
\text { GONÇALVES } \\
(2007) \\
\text { NBR 7200:1998 }\end{array}$ \\
\hline $\begin{array}{lr}\text { Fissuras } & \text { por } \\
\text { ausência } & \text { de } \\
\text { vergas } & \text { e } \\
\text { contravergas }\end{array}$ & $\begin{array}{l}\text { - Execução de vergas e/ou } \\
\text { contravergas. }\end{array}$ & $\begin{array}{l}\text { Execução das vergas e } \\
\text { contravergas por meio de } \\
\text { blocos canaletas, pré- } \\
\text { moldados e até mesmo } \\
\text { executadas diretamente no } \\
\text { local conforme } \\
\text { dimensionamento correto. }\end{array}$ & $\begin{array}{lr}\begin{array}{l}\text { Souza; } \\
(1998),\end{array} & \text { Ripper } \\
\text { NBR } \\
\text { 6118 } & \text { (ABNT, } \\
2014), & \text { Zanzarini } \\
(2016) . & \end{array}$ \\
\hline
\end{tabular}

\section{CONCLUSÕES}

Neste estudo foram observadas manifestações patológicas na fase construtiva da edificação, tais como fissuras, manchas de umidade, bolor e exsudação do hidróxido de cálcio do cimento hidratado. A presença de umidade proveniente da água de chuva em componentes da construção sem proteção por longo período que proporcionou o surgimento da maioria das manifestações observadas ou as agravou.

Outros problemas observados foram ausência ou execução incorreta de verga e contravergas que alertam para obras executadas sem fiscalização adequada, já que estes componentes são essenciais e amplamente conhecidos no meio da construção. Também foram identificadas fissuras em alvenaria causadas por função incorreta desta, utilizando-as como elementos estruturais para cobertura.

Os problemas patológicos observados evidenciam erros construtivos e de planejamento da obra. As manifestações patológicas na fase construtiva acarretam prejuízos financeiros e atraso na entrega da obra, de modo a evitá-las, o controle de execução da obra é essencial, visando garantir o desempenho e durabilidade da edificação ao longo do tempo. Porém quando percebidas na fase construtiva, deve-se realizar a intervenção correta rapidamente, visto que após finalizada a obra, as intervenções tornam-se mais custosas.

\section{AGRADECIMENTOS}

Os autores agradecem a Faculdade de Ciências e Empreendedorismo (FACEMP) pelo apoio e incentivo fornecido ao desenvolvimento do presente trabalho.

\section{REFERÊNCIAS}

Associação Brasileira de Normas Técnicas. (2013). NBR 15575: Edificações habitacionais Desempenho - Parte 1: Requisitos gerais, Rio de Janeiro. 
Associação Brasileira de Normas Técnicas. 2004. NBR 5410: Instalações elétricas de baixa tensão, Rio de Janeiro.

Associação Brasileira de Normas Técnicas. (2013). NBR 15575: Edificações habitacionais Desempenho - Parte 1: Requisitos gerais, Rio de Janeiro.

Associação Brasileira de Normas Técnicas. (2014). NBR 6118: Projeto de estruturas de concreto - Procedimento, Rio de Janeiro.

Brito, T. F. (2017). “Análise de Manifestações Patológicas na Construção Civil pelo Método GUT: estudo de caso em uma instituição pública de ensino superior”, João Pessoa.

Caporrino, C. F. (2018). "Patologias em alvenarias", 2. ed, Oficina de Textos, São Paulo.

Costella, M.F. et al. (2015). “Determinação da Tensão de Ruptura de Materiais Utilizados na Recuperação de Fissuras em Parede de Alvenaria de Vedação”. Universidade Comunitária da Região de Chapecó, Faculdade Meridional IMED, Mestrado em Tecnologia e Gestão da Inovação e Projeto de Mestrado em Engenharia Civil.

Farias, L.E.A. et al (2017). "Análise de Causas e Custos para Recuperação de Fissuras em uma Fachada de um Condomínio de Pequena Idade”. Faculdade Educacional Araucária, Curitiba, Paraná.

Gonçalves, E. A. B. (2015). "Estudo de Patologias e suas Causas nas Estruturas de Concreto Armado de Obras de Edificações”, Projeto de Graduação, UFRJ, Escola Politécnica, Curso de Engenharia Civil, Rio de Janeiro, 2015.

Helene, P. R. L. (1992). "Manual para reparo, reforço e proteção de estruturas de concreto". 2. ed, PINI, São Paulo.

Holanda, M. J. de O. (2015). “Técnicas Preventivas e de Recuperação de Estruturas de Concreto". Universidade Estadual da Paraíba.

Lapa. J. S. (2008). “Patologia, Recuperação e Reparo das Estruturas de Concreto”. Universidade Federal de Minas Gerais, Minas Gerais.

Lottermann, A. F. (2013). “Patologias em Estruturas de Concreto: Estudo de caso”, Universidade Regional do Noroeste do Estado do Rio Grande do Sul, Departamento de Ciências Exatas e Engenharias, Ijuí, Rio Grande do Sul.

Milititsky, J, Consoli, N.C e Schnaid, F. (2015). "Patologia das fundações”. Oficina de textos, São Paulo.

Oliveira, G. M. V. et al. (2019). "Análise de fissuras em alvenaria de vedação - Estudo de caso: uemg unidade de joão monlevade”, Research, Society And Development, [S.L.], 8 (12), p. 368121617.

Souza, V. C. de; Ripper, T. (1998). “Patologia, recuperação e reforço de estruturas de concreto”. 1. ed, Pini, São Paulo.

Thomaz, E. (1989). “Trincas em edifícios: causas, prevenção e recuperação”. 1. ed, Pini, São Paulo.

Verçoza, E. J. (1991). “Patologia das Edificações”. Sagra.

Werneck, L. P., Costa, T. A e Ferreira, B. C. S. (2020). "Estudo e avaliação do ciclo de vida do ambiente construído: uma análise sobre as possíveis manifestações patológicas que afetam edificações”, Brazilian Journal Of Development, [S.L.], 6, (9), p. 70460-70475. 